\title{
ENSINO DE CIÊNCIAS COMO CONTROLE DO ESTADO: 0 CASO DA ALEMANHA NAZISTA
}

\author{
FELIPE SANCHES LOPEZ ${ }^{*}$ \\ https://orcid.org/0000-0002-8621-5808 \\ JOSÉ LUÍS NAMI ADUM ORTEGA ${ }^{* *}$ \\ https://orcid.org/0000-0002-1791-543X \\ CRISTIANO MATTOS ${ }^{1 * *}$ \\ https://orcid.org/0000-0001-5927-8742
}

RESUMO: Neste trabalho, identificamos algumas das principais mudanças educacionais promovidas pelo governo alemão anteriormente à II Guerra Mundial. Tais mudanças objetivaram alterar a cultura existente no país, estabelecendo uma visão de mundo unificada baseada nos princípios nazistas, declarados antes mesmo da chegada do Partido Nacional-Socialista ao poder. A pesquisa realizada é de caráter qualitativo, de cunho histórico, e nela buscamos resgatar, com o apoio da metodologia linguística bakhtiniana, as formas típicas enunciativas expressas em materiais educacionais do período préguerra. Como resultado, reconhecemos que a educação científica foi transformada em uma educação para a guerra. Os conteúdos científicos estavam contextualizados em situações de guerra e ideais antissemitas. As modificações curriculares aumentaram a carga de disciplinas de condicionamento físico e a separação entre homens e mulheres. Como evidência, apresentamos exemplos de como a esfera política determinou modos de pensar a ciência e seu ensino, por meio de questões e exercícios didáticos introduzidos em materiais didáticos.

Palavras-chave: Currículo. Ensino de ciências. Nazismo. Controle educacional. Bakhtin.

\section{ENSEÑANZA DE LAS CIENCIAS COMO CONTROL ESTATAL: EL CASO DE LA ALEMANIA NAZI}

RESUMEN: En este trabajo, identificamos algunos de los principales cambios educativos promovidos por el gobierno alemán antes de la Segunda Guerra Mundial. Tales cambios

\author{
*Doutorando em Ensino \\ de Ciências. Programa de \\ Pós-Graduação Interunidades \\ em Ensino de Ciências. \\ Universidade de São Paulo. \\ São Paulo, SP, Brasil. \\ E-mail: fsanches@if.usp.br \\ **Doutor em Ensino de \\ Ciências. Programa de \\ Pós-Graduação Interunidades \\ em Ensino de Ciências. \\ Universidade de São Paulo. \\ São Paulo, SP, Brasil. \\ E-mail: \\ jose.ortega@colband.com.br \\ ***Professor Livre Docente. \\ Instituto de Física, \\ Universidade de São Paulo. \\ São Paulo, SP, Brasil. \\ E-mail: crmattos@usp.br
}

I Universidade de São Paulo, Programa de Pós-Graduação Interunidades em Ensino de Ciências, São Paulo, SP - Brasil.

II Universidade de São Paulo, Instituto de Física, São Paulo, SP · Brasil. 
tenían como objetivo modificar la cultura existente en el país, estableciendo una cosmovisión unificada basada en los principios nazis declarados incluso antes de que el Partido Nacionalsocialista llegara al poder. La investigación realizada es de carácter cualitativo, de naturaleza histórica, en la que buscamos rescatar, con el apoyo de la metodología lingüística bajtiniana, las formas enunciativas típicas expresadas en materiales educativos del período anterior a la guerra. Como resultado, reconocemos que la educación científica se ha transformado en educación para la guerra. Los contenidos científicos se contextualizaron en situaciones de guerra e ideales antisemitas. Las modificaciones curriculares aumentaron la carga de las disciplinas de preparación física y la separación entre hombres y mujeres. Como evidencia, presentamos ejemplos de cómo la esfera política determinó formas de pensar sobre la ciencia y su enseñanza, a través de preguntas y ejercicios didácticos introducidos en materiales didácticos.

Palabras clave: Currículo. Enseñanza de las ciencias. Nazismo. Control educativo. Bajtín.

\section{SCIENCE EDUCATION AS STATE CONTROL: THE CASE OF NAZI GERMANY}

ABSTRACT: In this article, we have identified some of the main educational changes promoted by the German government before World War II. Such changes aimed to change the existing culture in the country, establishing a unified worldview based on Nazi principles that were declared even before the National Socialist Party came to power. The research conducted is qualitative, of a historical nature, in which we seek to rescue, with the support of the Bakhtinian linguistic methodology, the typical enunciative forms expressed in educational materials from the pre-war period. As a result, we recognize that the science education was transformed into an education for war. The scientific contents were contextualized in situations of war and anti-Semitic ideals. Curricular modifications increased the burden of physical conditioning disciplines and the separation between men and women's curricula. As evidence, we present examples of how the political sphere determined ways of thinking about science and its teaching, through questions and didactic exercises introduced in didactic materials.

Keywords: Curriculum. Science teaching. Nazism. Educational control. Bakhtin. 


\section{INTRODUÇÃO}

No processo democrático, as forças que procuram incentivar o pensamento crítico e a possibilidade de emancipação de um povo, de uma nação, têm como instrumentos centrais os processos educacionais. Com eles é possível agir para determinar uma educação política na qual os sujeitos educacionais apresentem as potencialidades democráticas de ação individual e coletiva frente ao estado de direito.

Em outras épocas e sociedades, os processos educacionais tiveram funções distintas, ${ }^{1}$ por exemplo, um dos sentidos atribuídos à escola atualmente é o de um local privilegiado em que os cidadãos podem adquirir consciência do seu lugar na sociedade (HEATER, 2004). Esses processos cabem, quase exclusivamente, às instituições escolares, que se dedicam, nas sociedades capitalistas, à formação de uma massa de indivíduos capazes de assumir qualquer posto de trabalho. Assim, numa perspectiva marxista, a função da escola, desde seu início, acompanha o desenvolvimento econômico, determinando consciências em função dos processos produtivos já reproduzidos no ambiente e nos currículos escolares (MESZAROS, 2008).

A escola também pode ser vista como meio de transmissão de ideologias (FOUCAULT, 1987; GRAMSCI, 2019). Os costumes e hábitos são criados desde cedo nas escolas, como o modo de falar, de escrever, de se portar em sala de aula, a quem se submeter etc. Em situações social e economicamente estáveis, são poucos os alunos que questionam as regras e as estruturas de poder já estabelecidas dentro das salas de aula. Todos aprendem, desde cedo, seus lugares, quando levantar, quando falar, com quem falar, o que copiar, quando abrir o caderno, etc. Atitudes que expressam modos-de-ser esperados por quem detém os modos de produção da cultura escolar.

No Brasil, muitos têm defendido a ideia de que a verdadeira virtude democrática na educação é a "neutralidade ideológica" (GUILHERME; PICOLI, 2018) ou a "ausência de ideologia". ${ }^{2}$ Aqui advogamos pelo contrário, só uma escola plena de ideologias pode fazer brotar o pensamento crítico e o letramento político. Além disso, entendemos que a suposta eliminação das ideologias é que permite a entrada da mais sinistra das situações: a doutrinação por meio das forças políticas que determinam escolhas de conteúdo em currículos, livros didáticos e formação de professores, como se nenhum dos agentes escolares tivesse competência para fazê-lo.

Não só no Brasil, mas em todo mundo ampliou-se a propaganda que visa a desacreditar a ciência e o conhecimento científico produzido historicamente (ANDRADE, 2019; FERNANDES, 2020; FOLHA, 2019). Por isso, é fundamental entendermos como os processos de educação científica são alterados em momentos de acirramento político.

No caso que vamos explorar neste trabalho, a ascensão do nazismo na Alemanha no período anterior a $2^{a}$ Guerra Mundial, a escola passa a ser um local para determinar valores e modos de comportamento ligados à ideologia que sustentava o partido nazista. Essa transformação operou-se por meio de políticas que vão desde o acesso ao ensino até a diferenciação do currículo por gênero. Por exemplo, o currículo masculino enfatizava o estudo de armas, o condicionamento físico e os ideais nazistas; enquanto as disciplinas femininas orientavam-se à formação de futuras mães e esposas, especializadas nos assuntos domésticos e obedientes aos maridos e ao governo, o que acabou por dificultar o acesso das mulheres à carreira universitária. 
Tendo isso em vista, nosso objetivo geral é identificar algumas relações entre a ideologia dominante e os materiais didáticos elaborados para o ensino de ciências. Trabalhamos com enunciados típicos contidos nos livros didáticos e com relatos de sujeitos que viveram a escola nazista naquela época. Por meio da análise dos enunciados textuais de materiais pedagógicos, caracterizados pelos temas, composições e estilos característicos e seus cruzamentos com relatos históricobiográficos, identificamos como a ideologia nazista estava expressa, assegurando uma prática social e institucional da escola, que visava à manutenção das relações de poder, após a ascensão nazista na década de 1930, período no qual fica claro o papel da escola como correia de transmissão ideológica e dispositivo de controle social. Tais aspectos estão largamente abordados na literatura histórica, sociológica e política (e.g. SEGAL, 2014; HOBSBAWM, 2005; STERN, 2003; BADIA, 1971), aqui mostramos como essa determinação se estabeleceu por meio dos materiais didáticos da época.

\section{REFERENCIAL TEÓRICO}

Nas sociedades contemporâneas, atividade escolar é o espaço de relações por excelência, em que os sujeitos entram em contato com os processos educativos planejados e com o conhecimento científico produzido e estabilizado no processo de desenvolvimento histórico da humanidade, com o objetivo de se preparem para a vida em sociedade e para o futuro (GRAMSCI, 2019). Nessa perspectiva, a escola torna-se um lugar privilegiado para entendermos como a sociedade que a sustenta está organizada e como pretende fundar seu futuro. Assim, o currículo e os materiais educacionais são objetos importantes para compreendermos, concretamente, o estabelecimento das relações entre as ideologias dominantes e os instrumentos educacionais numa determinada totalidade social e histórica. Para Gramsci (2001), a escola é o local de formação dos intelectuais e elaboração da vida cultural. A materialidade das escolhas do tipo de intelectual e de cultura está manifestada nas legislações educacionais, nos modos de formação de professores e nos currículos escolares, mediações que se estabelecem e se realizam determinadas pelo grupo social hegemônico (ou classe hegemônica) dessa sociedade.

Os grupos sociais não exercem sua hegemonia diretamente no ambiente escolar, como dissemos ela é concretizada, por exemplo, nos diferentes níveis hierárquicos em que o currículo se manifesta, seja o da escola ou o do país, definindo caminhos que os estudantes percorrerão durante sua vida escolar. No currículo são definidos os conteúdos e sua ordenação, logo, os graus de dificuldade que devem ser superados e sua sequência (SACRISTÁN, 2013). É no currículo que se expressam certos objetivos específicos pretendidos na formação das pessoas e, frente a tal intencionalidade, não podemos ignorar as dimensões de controle que se pretende exercer nos estudantes (GOODSON, 2001). Assim, por meio do currículo, a classe hegemônica define o papel dos estudantes na sociedade futura. Ao definir um currículo, não apenas está se decidindo o que um estudante pode ser, mas também o que ele não pode ser, uma vez que escolhas deliberadas e delimitações intencionais implicam a impossibilidade de determinados caminhos (MUSGROVE, 1968). Nessa ótica, Foucault $(1998,2008)$ posiciona a Escola no mesmo patamar que o das instituições hospitalares e prisionais, cujo objetivo último é “docilizar" os indivíduos 
por meio da disciplina. Bourdieu (1992), por sua vez, usa o conceito de habitus para afirmar que o individual, o pessoal e o subjetivo são sociais e coletivamente orquestrados, uma "subjetividade socializada" (idem, p. 101). Assim, o habitus escolar pode ser entendido como "objetivado nos corpos na forma de disposições duráveis que reconhecem e atendem às demandas específicas de uma determinada área institucional de atividade" (BOURDIEU, 1990, 58), dando suporte à ideia de "habitus institucional" que ajuda a reconhecer os discursos e práticas dominantes da organizações particulares como violência simbólica "na qual o babitus escolar afirma e mantém seu domínio sobre os indivíduos que não se encaixam 'instintivamente' nesse ambiente" (MCNAMARA HORVAT; LISING ANTONIO, 1999, p. 320).

Dessa forma, os processos educacionais são constituídos por uma hierarquização de forças, que submetem os estudantes a controles rigorosos de horários, de acesso a espaços, de condutas e comportamento, cujo desrespeito implica a distribuição de penalidades, limitações, proibições e obrigações. Assim, o processo educacional pode ser entendido como uma forma de dominação, implicando o exercício de uma disciplina contínua e perpétua (FOUCAULT, 1998). A passividade dos estudantes, imposta pela disciplina, desenvolve neles uma atitude de consumo com relação aos conhecimentos apresentados, como se fossem produtos acabados, produzidos por outros. Na perspectiva da lógica formal, estabelece-se, nos objetivos formativos, um dilema entre emancipação e alienação dos estudantes (CAMILLO; MATTOS, 2019). A reprodução dos conhecimentos sem uma ação, sem uma consciência crítica, transforma esse conhecimento em saber dogmático, que determina o que pode e não poder ser dito, o que pode e não pode ser pensado. Com esse tipo de atividade, a consciência e a prática dos jovens desenvolvem-se determinadas por aquilo que é aceito como verdade em uma sociedade (GRAMSCI, 2001).

\section{METODOLOGIA}

Dado nosso enquadramento teórico - o materialismo histórico dialético numa perspectiva gramsciana - concentramos nossos esforços em evidenciar relações concretas que sustentam a relação entre a ideologia nazista e os enunciados expressos nos materiais didáticos escolares, que dão acabamento a essa ideologia.

Para tanto, realizamos um levantamento bibliográfico em busca de materiais didáticos acessíveis e selecionamos materiais originais produzidos naquele período histórico. Além disso, para caracterização da ideologia do período, valemo-nos de uma obra fundante do período nazista: o livro "Minha Luta", de Adolf Hitler (1941), que subsidiou e determinou as diretrizes educacionais da época.

Ainda, investigamos dois livros didáticos originais da época que serviram de base para a análise enunciativa textual das diretrizes que nortearam o ensino da disciplina de física. Um deles é de autoria de Phillip Lenard (1936), prêmio Nobel de física e representante icônico do período que ficou conhecido como "A Física Alemã". O segundo livro é de Erich Günther (1936), autor do livro de apoio a professores para o ensino da "Física da Defesa". Além dessas referências primárias, duas referências secundárias foram importantes para o estudo, pois caracterizam o estado da educação no período estudado. O primeiro texto é o da historiadora Lisa Pine (2010) e o segundo texto o de Erika Mann ${ }^{3}$ (1938). O 
livro de Mann foi publicado pela primeira vez em 1938 e, além de relatos sobre a sociedade nazista, traz relatos baseados na experiência de sua vivência pessoal na escola nazista. Além disso, para caracterizar melhor o período histórico, utilizamos textos de historiadores como Hobsbawm (2005) e Carr (2001), de caráter mais geral, e de Shirer (2008) e Evans (2016), que estão mais centrados, no processo específico de ascensão de Hitler. Também utilizamos a obra de Lutz (1922) para a contextualização histórica sobre a República de Weimar. Outra importante fonte utilizada para caracterização do ensino nazista no período foram os documentos históricos contidos nos oito volumes do livro Nazi Conspiracy and Agression ${ }^{4}$ (EUA, 1946) que possui mais de quatro mil documentos traduzidos na íntegra ou parcialmente, utilizados pelos responsáveis da acusação jurídica nos julgamentos de Nuremberg contra a liderança militar, política e econômica da Alemanha Nazista.

Mantendo o enquadramento teórico-metodológico, para a análise enunciativa dos materiais didáticos citados, foi utilizada a análise linguística numa perspectiva metodológica bakhtiniana. ${ }^{5}$ Nela, a forma enunciativa, estabilizada socialmente, que aparece nos registros levantados, é um momento aparente do movimento da atividade social, movimento que produz e reproduz a própria sociedade (VOLÓCHINOV, 2017). Nesta investigação, analisamos os materiais históricos disponíveis com as categorias de (i) conteúdo temático, que diz respeito aos temas e conceitos cotidianos dominantes mobilizados pela disciplina de física predominantemente; (ii) estrutura composicional, referindo-se à hierarquia dos temas, suas organizações, sua estrutura hierárquica; e (iii) estilo, a forma com que os temas são apresentados, quais recursos linguísticos e repertórios lexicais são utilizados. (BAKHTIN, 2003). A guisa de exemplo, essas categorias auxiliam-nos a explicitar os sentidos que determinam certas escolhas temáticas em detrimento de outras: estudar movimento de aeronaves e tanques, em vez do estudo de veículos comuns do cotidiano, a energia produzida num bombardeio, em vez da energia em usinas, são exemplos de escolhas temáticas. Quanto a estrutura composicional, ela é determinante para entendermos as sequências, as ênfases atribuídas aos conteúdos escolhidos: optar por estudar movimentos e forças de forma conjunta ou separada, ou mesmo ensinar magnetismo, antes de eletricidade (ORTEGA et al., 2017), são exemplos de composição. Finalmente, quanto ao estilo, aqui são determinadas as relações entre forma e conteúdo, ou seja, como cada conteúdo deve ser apresentado: aulas experimentais com prática de laboratório, leitura de textos com realização de verificações de leitura, recursos audiovisuais e debate em sala, são alguns exemplos. Essa categoria, envolve a relação entre os aspectos atitudinais e procedimentais e os conteúdos mobilizados. Como mostram alguns documentários do período, ditados em voz alta e atividades práticas são uma tônica no estilo educacional da época, ${ }^{6}$ que evidenciam o sentido disciplinador das atividades escolares.

Com essas categorias pretendemos caracterizar as escolhas, as visões de mundo, os enquadramentos (MEDVIÉDEV, 2010), critérios de seleção que emergiram da relação entre esferas educacionais e políticas na Alemanha nazista de 1933 até 1939, dando especial atenção às formas como as ciências naturais foram utilizadas nesse período escolar. 


\section{ASPECTOS DA EDUCAÇÃO E DA CIÊNCIA PARA O NAZISMO}

Como já afirmamos, as bases da educação nazista foram delineadas no marco ideológico estabelecido pelo livro Minha Luta, escrito por Hitler (1941), durante os anos em que esteve preso. No texto, Hitler atribui muitos dos problemas existentes na Alemanha a um sistema de ensino falho que, segundo ele, estimulava o medo de assumir responsabilidades, estava limitado à produção de conhecimento puro e não de habilidades práticas. Dessa maneira, "o resultado [era] a formação de homens que não eram fortes, mas flexíveis 'sabichões"'. (p. 323). Esse tipo de ensino, para Hitler (1941), também causava falta de devoção generalizada aos ideais nacionais e à formação de cidadãos cujos conhecimentos eram aproveitados por outras nações, dado que, segundo ele, os melhores profissionais deixavam a Alemanha para trabalhar em outros países.

Após tais críticas ao sistema educacional vigente, Hitler propõe uma "visão de mundo" (Weltanschaunng) que seria definitiva e uniformemente aceita como solução, não somente dos problemas da educação, mas de toda a sociedade alemã. A importância da educação nazista não se restringia à escola, dado que meios de comunicação possuíam também um papel fundamental na doutrinação da sociedade, uma vez que a propaganda seria a continuidade do trabalho educacional na vida adulta (HITLER, 1941):

É, por isso, dever do Governo velar pela educação do povo e impedir que o mesmo tome orientação errada, fiscalizando a atuação da imprensa em particular, pois a sua influência sobre o espírito público é a mais forte e a mais penetrante de todas, desde que a sua ação não é transitória, mas contínua. Sua imensa importância está no fato da uniforme e persistente repetição da sua propaganda. (p. 330)

Hitler defendia que o governo deveria controlar as informações em rádios e livros para garantir que as pessoas não fossem manipuladas por grupos com ideais distintos, tipicamente marxistas e judaicos, prejudiciais à Weltanschanung proposta (LEWY, 2016).

O Estado deve controlar esse instrumento de educação popular com vontade firme e pô-lo ao serviço do Governo e da nação. (HITLER, 1941, p. 336)

Um aspecto central da educação nazista, consonante com essa visão de mundo, era o privilégio de conteúdos temáticos relacionados ao condicionamento físico e ao conhecimento racial, como revelado nas palavras de Hitler:

Instrução formal nas ciências deve ser considerada última em importância. Por tanto, o Estado que é baseado na ideia racial deve começar com o princípio de que uma pessoa cuja educação formal em ciências é relativamente pequena, mas ela é sã e robusta, de um caráter firme e honesto, pronta e hábil a tomar decisões e dotada de força de vontade, é um membro mais útil da comunidade nacional do que fracos que são sábios e refinados. Uma nação composta de homens instruídos que são fisicamente fracos, hesitantes sobre decisões de vontade e timidamente pacifistas, não é capaz de 
assegurar sua própria existência nessa Terra. (HITLER, 1941, p. 651).

O preparo físico ganha centralidade na vida educacional, proporcionando que os alunos participem de atividades extraescolares de treinamento físico, não só com o objetivo de melhorar a saúde e o condicionamento físico dos jovens, mas visando à preparação para o alistamento no exército e ao sucesso na vida militar. Participaram, desse tipo de formação, grupos jovens, já constituídos na sociedade Alemã, como o grupo Juventude Hitlerista ${ }^{7}$ e a Liga das Garotas Alemãs, ${ }^{8}$ todos formados de jovens entre 10 a 18 anos (EPSTEIN, 2015; PINE, 2017).

Para Hitler, a educação dos diferentes sexos baseava-se essencialmente em treinamento físico; no anti-intelectualismo e no significado de raça (PINE, 2010). Segundo Mann (1938), as crianças eram o grupo mais afetado pelas mudanças propostas pelo governo autoritário, pois um adulto ainda poderia ter sua vida relativamente normal, desde que fosse adepto ao Partido. Já, a criança alemã seria "uma criança nazista e nada mais", pois "frequenta uma escola nazista; pertence a uma organização da juventude nazista; os filmes que a ela são permitidos, são todos filmes nazistas. Toda sua vida, sem qualquer exceção, pertence ao Estado Nazista" (MANN, 1938, p. 19). Hitler (1941) defendia mudanças na Alemanha com relação à educação, apontando que a educação feminina, também focada no treinamento físico, tinha um objetivo supremo de mostrar que as garotas iriam se tornar mães sadias e que, além das armas, deveriam estar preparadas para carregar seus filhos.

\subsection{A ESCOLA E O CURRÍCULO}

Não era apenas o Ministro da Educação alemã, Bernhard Rust, o principal agente das mudanças educacionais que aconteciam no Reich. Como quase nenhuma instrução direcionada à educação vinha diretamente de Hitler, vários outros líderes nazistas, como Heinrich Himmler e Joseph Goebbels, assumiram o papel de intervir politicamente na educação determinando diretrizes educacionais, o que enfraquecia o poder de comando de Rust (PINE, 2017).

As mudanças implementadas implicavam, para os jovens do sexo masculino, a escolha de uma formação focada em Línguas Modernas, Ciências ou Clássica. Para as jovens meninas, só havia a escolha entre uma formação em Línguas Modernas ou em Economia Doméstica, sendo que essa última escolha, impediaas de ingressar no Ensino Superior. Tais mudanças curriculares direcionadas às jovens causaram um declínio em seus ingressos nas universidades.?

Nos momentos iniciais do governo, não houve mudanças drásticas nos conteúdos dos livros didáticos. Reutilizaram-se os livros vigentes, que foram reimpressos com fotografias de Hitler, slogans nazistas e bandeiras da suástica. Somente no final da década de 1930, ocorreu a primeira substituição dos livros didáticos, por aqueles alinhados aos nazistas, direcionados para o público estudantil. Ao longo do tempo, com o argumento de modernizar as escolas, o Partido Nazista fechou escolas religiosas, a fim de centralizar o ensino e impedir que outras ideologias conflitantes fossem disseminadas entre os estudantes (PINE, 2017). Todas essas mudanças iniciais favoreciam a construção de um discurso monológico homogeneizador e regulador das práticas sociais. Como ilustra o filme 
de Holland (1990), os alunos não só viviam em constante vigilância dos professores, mas também os próprios professores eram observados pelos alunos. Obrigados a participar da Juventude Hitlerista, os jovens eram incentivados a delatar seus professores caso ensinassem algo distinto dos preceitos nazistas (EVANS, 2016).

Como uma primeira alteração digna de nota, nessas primeiras publicações, Mann (1938, p. 54), testemunha histórica dessa fase, aponta o surgimento de uma "escala de valores, em ordem de importância" para apresentação novos conteúdos temáticos escolares determinados por Hitler, na seguinte estrutura composicional: (i) Tendências hereditárias; quadro geral de raças; ${ }^{10}$ (ii) $O$ caráter, (iii) $A$ constituição física ou "corpo"; (iv) Conhecimento. Esse último, não se referia ao conhecimento científico da época, pois a preparação para a guerra, que passa a ser o conteúdo temático principal, modulava a nova concepção de ciência, nomeada como "Ciência da Defesa" (Wehrwissenschaft) (MANN, 1938).

Como todas as áreas das ciências naturais estavam moduladas pelo conteúdo temático militar, baseavam-se em exemplos que se relacionavam com manipulação de armamentos, logística e estratégias de batalha. A disciplina de física, em particular, foi praticamente transformada em propriedade do nazismo, passando a ser nomeada de "Física da Defesa" (Wehrphysik) (MANN, 1938; PINE, 2010). A estrutura temática, introduzida e estabilizada pela militarização da Ciência, refletia e refratava o que acontecia naquela sociedade, incluindo os aspectos da discriminação racial, explícitos na área de pesquisa em física. Nela, nem toda produção da pesquisa em física pertenceria a essa "nova física" - a Física Alemã ou Ariana, que se tornou um movimento muito amplo entre os cientistas alemães que, em parte, não consideravam corretas as ideias de Einstein sobre a Relatividade (BALL, 2014). Assim, grande parte dos temas sobre o conhecimento físico do início do século XX, não apareceu nos quatro volumes do livro didático de física escrito pelo já prêmio Nobel Phillip Lenard (1936).

No caso do currículo masculino, a composição dos temas refletia a estrutura composicional proposta por Lenard (1936). Assim sendo, eram apresentados, de forma ainda comum nos dias de hoje em diversos materiais educacionais de nossa área, a seguinte sequência de conteúdos: mecânica, termodinâmica, óptica e eletricidade. A avaliação desses conteúdos era realizada por meio de exercícios com estilo da Física da Defesa, contextualizados em situações de guerra ou de economia de guerra (como veremos mais adiante). Já no currículo feminino, apesar da estrutura composicional ser a mesma, seu estilo e tema eram outros, mais ligados ao cotidiano das mulheres, orientados a relações práticas da física com aparatos domésticos e da saúde.

No ensino das outras ciências, essa diferença de estilo se mantinha. Enquanto no ensino da química, para as jovens, o conteúdo específico era sempre contextualizado em temas como alimentos, objetos domésticos e detergentes, para os jovens os conteúdos se referiam aos gases venenosos e compostos explosivos. No ensino da biologia, havia um conteúdo temático comum: o problema da hereditariedade. Assim, os temas referiam-se à hereditariedade de características físicas, à hereditariedade de características mentais e espirituais, à hereditariedade de fragilidades e doenças, à hereditariedade de características físicas e espirituais da "raça alemã", ao cuidado da herança racial, à lei de seleção e aos povos judeus 
e alemães. Tais temas, cujo estilo se manifestava por discursos autoritários que enfatizavam a vigilância da coletividade, a habilidade em detectar o diferente, a ênfase na distinção racial por meio da caracterização e determinação das diferenças genéticas, focava a identificação e valorização das características arianas frente às outras raças (PINE, 2010). Para o currículo feminino de biologia, ainda eram acrescentados outros conteúdos temáticos como o instinto maternal, o papel de mãe e esposa e primeiros-socorros para a preservação dos exemplares da "nova raça". Além disso, à estrutura composicional da química eram acrescentados temas como o da reprodução e criação animal, estudos práticos para o cuidado de bebês e crianças pequenas, cuidado com doentes e primeiros socorros.

\subsection{OS PROFESSORES E A NSLB}

Para o sucesso desse empreendimento, eram necessários quadros eficientes que aderissem completamente ao projeto ideológico. A Liga dos Professores Nacionais Socialistas ou NSLB ${ }^{11}$ foi formada antes da tomada do poder pelos nazistas, em abril de 1929. Em seu início, contava com professores de ideais radicais, em sua maioria professores entre 20 e 40 anos, desiludidos com a profissão e com a república de Weimar. Denunciando a desvalorização da profissão, as promessas da Liga eram justamente as de mudar esse quadro de relações limitantes presente no país como um todo (PINE, 2010).

Depois da tomada de poder do Partido Nazista em 1933, houve um aumento expressivo das associações à NSLB que, segundo Pine (2010), tinha como principal motivo a manutenção de cargos e não se estruturaram por afinidades com a ideologia partidária. Cada vez mais professores começaram a aderir à NSLB, chegando, em 1939, a dois terços dos professores alemães a participar dos chamados campos da liga. Nesses campos realizavam-se atividades de treinamento físico compulsório para professores com idade inferior a cinquenta anos e conferências sobre as diretrizes educacionais oficiais (PINE, 2017).

A Liga possuía duas funções principais, a de fiscalizar a fidelidade dos professores com o partido, a fim de assegurar promoções e indicações, e a de doutrinar os professores (PINE, 2017). Outra mudança que influenciou o aumento do número de professores que aderiram à Liga foi um anuncio feito em outubro de 1935, no qual se determinava que os professores associados à NSLB, especialmente aqueles que já haviam participado da Juventude Hitlerista ou da Liga das Garotas Alemãs, deveriam ser considerados como prioridade nas contratações nas instituições escolares (EUA, 1946). Dessa forma, a própria validação profissional se dava em função da adesão ideológica dos professores.

\subsection{O MOVIMENTO WEHRPHYSIK}

Chegando ao poder, os nazistas promoveram uma série de mudanças curriculares. As disciplinas de ciências, tiveram menor prioridade, em detrimento do treinamento e condicionamento físico, considerados disciplinas essenciais na formação dos estudantes (EUA, 1946; MANN, 1938; PINE, 2010). Entretanto, o ensino de ciências, como dissemos, passou a ser dominado por um conteúdo temático 
que modulava a resolução de problemas, formulados para situações típicas de ataque e defesa em situações de campo de batalha (MANN, 1938; PINE, 2010). No caso do ensino de química, também chamada de Química da Defesa, num estilo bem pragmático, eram enfatizados temas relativos ao uso de bombas e a como se defender delas durante um ataque. Também na física, o estilo dos exercícios, expressava as necessidades do conteúdo temático, ao elaborar situações-problema sobre balística, armas, aeronáutica, logística etc. A maior parte dos temas e ênfases baseava-se nos conhecimentos obtidos durante a Primeira Guerra Mundial. O movimento ficou conhecido como Wehrphysik, algumas vezes traduzido como "Física das Armas" (MANN, 1938; PINE, 2010, 2017), ou "Física da Defesa" (HENTSCHEL, 1996).

Em consonância com essa perspectiva militarizada, o treinamento físico ocupou espaço considerável na grade curricular diminuindo a carga horária de outras disciplinas, principalmente da educação religiosa, criando novas disciplinas como boxe e cross country. A demonstração de aptidão física pelos estudantes, tornou-se critério de seleção e progresso em direção aos níveis superiores de ensino (PINE, 2017).

Com a iminência da guerra, surgiu uma mudança das estratégias no ensino de ciências, que tomaram forma com a emergência do movimento Wehrwissenschaft, que se refere mais amplamente, agora, à Ciência das Armas ou da Defesa. Tal mudança pretendia retomar e assegurar a importância do ensino de física em um currículo dominado pelo condicionamento físico e pelo ensino de biologia, temas que se retroalimentavam na procura da confirmação da superioridade genética ariana.

A estratégia de convencimento das lideranças Nazistas era evidenciar a importância do ensino de física para a formação dos jovens. Assim, enfatizava-se sua aplicação sistemática para preparação militar, abordando temas como engenharia de veículos, armas e balística, aviões, proteção de ataques aéreos entre outros. Esse movimento introduziu radicalmente o tema da militarização no ensino de física determinando sua estrutura composicional, completamente aderida aos conteúdos pragmáticos para a imersão dos jovens na guerra que se iniciava (HENTSCHEL, 1996).

Apesar de não ter sido utilizado diretamente nas mudanças curriculares, o livro de Lenard (1936) influenciou professores de física ligados ao Partido Nazista (BEYERCHEN, 1977), como foi o caso do Dr. Erich Günther (1936), cujo livro "Física da Defesa: um guia para professores", ${ }^{12}$ expressa bem o estilo em que o conteúdo temático se concretizou para os propósitos didáticos.

O livro modulado pelo conteúdo temático da "Física da Defesa", apesentava uma estrutura composicional com tópicos de acústica focada em audição direcional; comunicação acústica, óptica e elétrica aplicada em equipamentos de observação e detecção; aeronáutica; meteorologia; finalizando com temas sobre engenharia pioneira, uso de máscara de gases, células fotoelétricas, e fotografias em condições de névoa, até então temas atípicos no ensino de física. O tema das células fotoelétricas, apesar de serem uma derivação da produção científica de Einstein (efeito fotoelétrico), foi aceito pela sua grande utilidade e aplicação militar.

Dada a importância de Lenard para a física na Alemanha, seu livro "Física Alemã em Quatro Volumes"13 (LENARD, 1936) foi determinante para moldar uma visão de ciência vigente na Alemanha nazista durante o governo de Hitler. Além disso, o livro modulado pelo conteúdo temático da "Física Alemã", determinava um enquadramento bem específico de física, representada por uma estrutura 
composicional de conteúdos de pesquisa exclusivos da "Física Alemã", ou seja, não incluía conteúdos científicos produzidos por físicos de outras raças. O livro e as escolhas de Lenard, refletiam o modo pelo qual as pesquisas de física estavam sendo consideradas nesse período e, consequentemente, seu ensino. Heisenberg (1996) relata, em sua autobiografia, que teria sido perseguido na comunidade científica por concordar com a Teoria da Relatividade de Einstein, que não era considerada Física Alemã, logo não deveria ser pesquisada ou ensinada. Lenard (1936), organizou nos quatro volumes de sua obra didática a seguinte estrutura: mecânica, acústica, termodinâmica e eletromagnetismo, não introduzindo tópicos de física moderna, em particular os conteúdos de relatividade.

$\mathrm{Na}$ próxima seção, apresentaremos uma análise um pouco mais detalhada dos estilos característicos que emergiram em materiais didáticos modulados pelo conteúdo temático da "Ciência da Defesa".

\section{MATERIAIS DIDÁTICOS}

\subsection{FÍSICA DA DEFESA: UM GUIA PARA PROFESSORES}

O livro Física da Defesa foi produzido por Erich Günther, em 1936, para ser utilizado por professores e alunos de nível mais avançado. De acordo com Günther (1936), o estudo da física não tinha somente o propósito de despertar a habilidade no uso de armamentos, mas também de despertar a vontade de usá-las, mostrando vantagem e meios técnicos para sua melhor utilização como instrumento de defesa.

Esse livro está organizado em oito capítulos: Ver, medir, mirar; som e medidas sonoras; doutrina da bala; instalações de comunicação; lições de voo; meteorologia; mecânica pioneira; diversos. Com mais de 290 exercícios divididos em cinco categorias: experimentos em classe; experimentos práticos para os estudantes; produção de equipamentos; experimentos em campo aberto; e exercícios teóricos.

Os conteúdos temáticos e a estrutura composicional seguem aquelas apresentadas no livro Física Alemã, de Lenard (1936). Porém, o estilo escolhido, de operação de combate, é muito significativo.

A Figura 1 contém dois exemplos de imagens presentes no primeiro capítulo do livro, intitulado "Ver, Medir, Mirar". A Figura 1a é usada na seção "Mira telescópica de metralhadoras" para exemplificar onde as miras podem ser encontradas em armas e como elas são utilizadas. Já a Figura 1b mostra um equipamento de guerra utilizado para determinar distâncias. É dito que esse equipamento foi utilizado pelos militares alemães antes de qualquer outro exército. 
Figura 1. Exemplos de imagem do capítulo "Ver, Medir, Mirar". A imagem 1a representa uma mira telescópica em um rifle, enquanto $1 \mathrm{~b}$ mostra um telêmetro de guerra

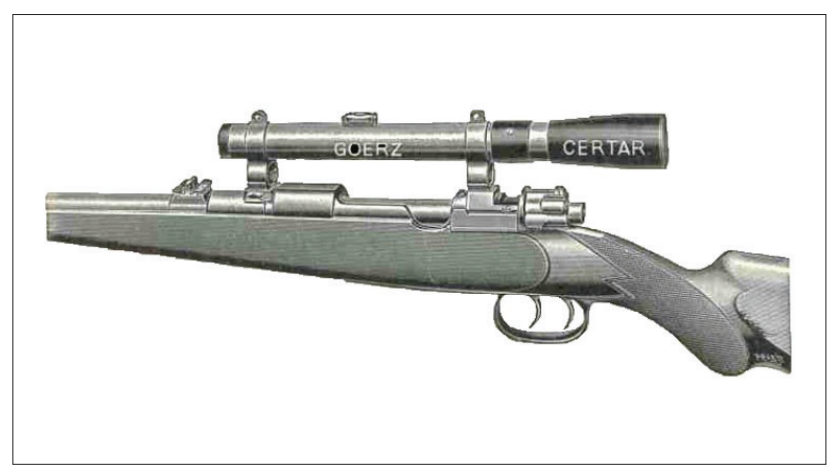

1a

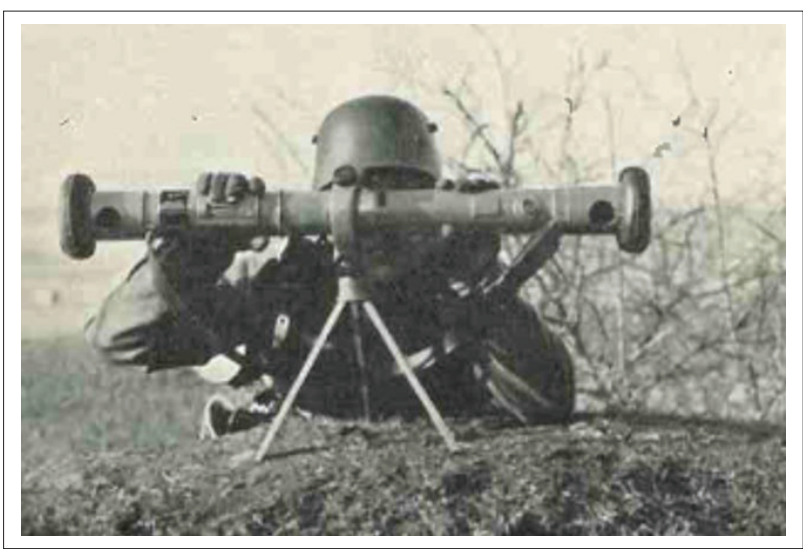

1b

Fonte: Günther (1936, p. 23 \& 27)

Ao tratar sobre mira, são apresentados alguns problemas que podem fazer com que o atirador erre seu alvo. O exercício seguinte propõe a situação em que a mira de uma arma está iluminada:

"Que tipo de erro de mira é causado por uma massa de mira ${ }^{14}$ fortemente iluminada de cima, da esquerda, da direita? (Ilusão de óptica: áreas brilhantes parecem maiores do que são. Com o lado esquerdo iluminado, o lado esquerdo da massa de mira parece muito grande. Se a massa de mira parece estar no meio, na verdade está fixado à direita. Resultado: atire para a direita!) Ao atirar de um rifle, pode ser necessário alternar entre a alça de mira e a massa de mira." (GÜNTHER, 1936, p. 31, trad. nossa) 
Günther (1936, p. 34) também explica que a presença de vento pode desviar o projétil do alvo, por isso, deve-se levar em consideração a velocidade do vento para atingir o alvo, o exercício abaixo segue a explicação:

“Qual a correção necessária se o vento desvia o projétil em $50 \mathrm{~m}$ para o lado a cada $1000 \mathrm{~m}$ percorridos? (Assuma a trajetória do projétil como movimento retilíneo uniforme, com velocidade média!)" (trad. nossa)

Os dois exercícios acima demonstram as dificuldades para se atingir um alvo em situações reais. Na primeira, pode-se imaginar uma situação em que o Sol está brilhando forte; enquanto a segunda diz respeito a presença de ventos fortes, mas também pode ser utilizada para alvos em movimento.

É importante notar que o exercício sobre atirar na presença de vento está se referindo à composição vetorial de movimentos e outro estilo poderia ter sido escolhido para o exercício numa perspectiva mais formalista. Entretanto, foi feita uma escolha estilística vivencial de guerra com o intuito de familiarizar os estudantes a situações similares.

No capítulo "Som e Medidas Sonoras" é proposto um exercício prático sobre escuta direcional (GÜNTHER, 1936, p. 43). O exercício propõe uma atividade prática com quatro etapas a ser realizada em um campo aberto com toda a turma:

“a) Um aluno fecha os olhos, outro fica à sua frente a uma certa distância e emite sinais sonoros (batendo [em algo], batendo palmas, estalando [os dedos ou a língua]). O primeiro aluno indica se ele suspeita de a fonte de som estar à sua frente mais à esquerda ou à direita.

b) Os alunos formam um círculo de 10 a $20 \mathrm{~m}$ de diâmetro; alguém se coloca ou se senta com os olhos fechados no centro. Um dos alunos do círculo emite sinais sonoros ao sinal do professor. $\mathrm{O}$ aluno no centro do círculo aponta na direção em que suspeita que fonte sonora esteja; sob certas circunstâncias, ele se vira, sempre com os olhos fechados, até achar que tem a fonte sonora à sua frente.

c) Modificação do último exercício: Um aluno designado pelo professor tenta engatinhar o mais silenciosamente possível na direção do aluno no meio do círculo. Este ouve os sons do rastejamento e aponta na direção em que suspeita que o rastejamento esteja acontecendo, o aluno, quando descoberto, deve retornar ao seu lugar. Mas se o homem rastejante consegue alcançar o ouvinte, ele toma seu lugar e o que estava no centro toma seu lugar no círculo.

d) Os alunos são distribuídos aleatoriamente na praça. Dois se aproximam dos olhos dos observadores, um terço emite sinais sonoros. Os dois observadores apontam na direção em que suspeitam da fonte sonora. A interseção das duas direções do rolamento fornece a localização da fonte sonora." (trad. nossa) 
Pela sequência proposta por esta estrutura composicional, quando chegam a esse exercício, os estudantes já são capazes de realizar medidas, de mirar e sabem utilizar alguns equipamentos de guerra, como os que foram mostrados acima. Sendo assim, nesse momento, preparam-se para identificar a fonte sonora em um local aberto e, em conjunto com seus pares, triangular a posição de uma possível ameaça, bem como elaborar formas de defesa e ataque.

A seguir temos um clássico exemplo de um experimento de pêndulo balístico, comum em sequências de conservação de momento e conservação de energia nos livros de hoje. Aqui ele aparece extensivamente analisado numa série de situações experimentais. Esse recurso familiariza o estudante com o poder de fogo dos armamentos.

O pêndulo é um bloco de madeira $H$ suspenso perpendicularmente ao chão e possui uma placa de aço St como mostrado na Figura 108..$^{15}$ A suspensão do pêndulo é mostrada de frente na figura 108a. De modo a determinar a profundidade de penetração $\mathrm{S}$ do projétil com precisão, o bloco $\mathrm{H}$ consiste em uma série de discos de madeira planos e empilhados, que estão presos por duas braçadeiras $K_{1}$ e $K_{2}$. O pêndulo desenha, ao oscilar, em uma tira de papel $S_{p}$ fixa atrás dele em $C$ com atrito insignificante, que corre em um prato $T i$ e em um guia $F$. É essencial que o projétil atinja o bloco de madeira no seu "centro de impacto" B. Para garantir isso, a arma deve ser firmemente fixada e os primeiros tiros devem ser mirados em um disco de cartão $P$ colocado no plano do pêndulo. Uma caixa de areia pode servir como um coletor de balas (GÜNTHER, 1936, p. 91-92, trad. nossa).

Esse exercício é classificado pelo autor como uma demonstração prática a ser realizada pelo professor em aula. Novamente, um conteúdo temático comum e ensinado até os dias de hoje foi apresentado com um estilo expresso em proposições de prática de guerra. O professor é incentivado a usar uma arma dentro da sala de aula na situação experimental proposta. Nesse, como nos exercícios anteriores, as escolhas estilísticas são propositadas e visam à normalização de situações de guerra para a preparação dos estudantes. 
Figura 2. Esquema do exercício sobre pêndulo balístico, onde (a) representa o esquema visto de frente e (b) 0 esquema visto de lado

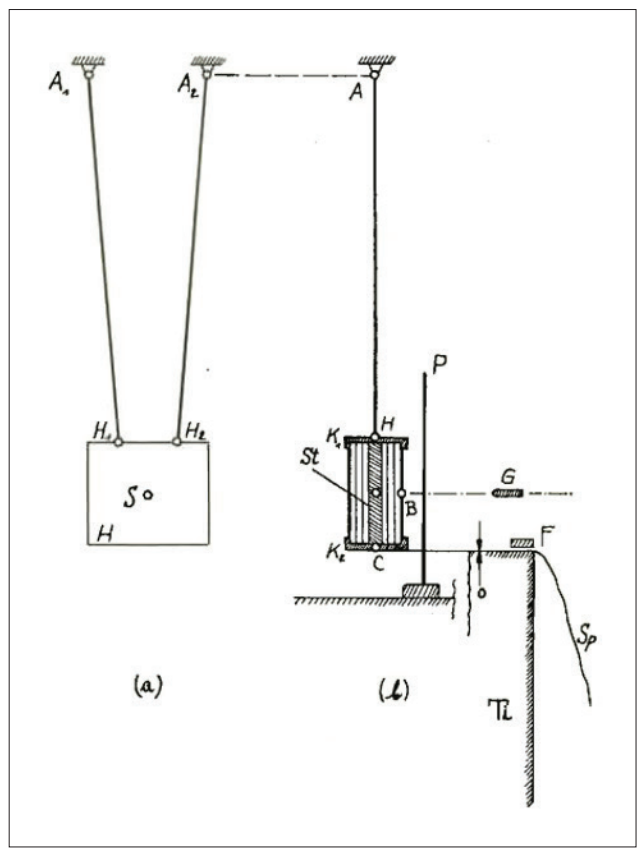

Fonte: Günther (1936, p. 91)

\subsection{EXEMPLOS DE OUTRAS CIÊNCIAS}

Nesta seção, analisamos exemplos retirados de fontes secundárias e que dizem respeito a outras disciplinas, como matemática, química e biologia. Os exercícios apresentados a seguir referem-se ao conteúdo temático do cálculo algébrico e são apresentados igualmente para aplicações em situações reais. No primeiro caso, analisa-se os percentuais da capacidade de carga dos aviões de combate:

Um avião de bombardeamento pode ser carregado com uma bomba explosiva de 35 quilogramas, três bombas de 100 quilogramas, quatro bombas de gás de 150 quilogramas, e 200 bombas incendiárias de um quilograma. Qual é a capacidade de carga? Qual a porcentagem de cada tipo de bomba? Quantas bombas incendiárias de 0,5 quilogramas poderiam ser adicionadas se a capacidade de carga fosse aumentada em $50 \%$ ? (KOCH, 1973, p. 100)

O segundo está contextualizado no desprezo por aqueles que não se enquadravam nos ideais de pureza racial ariana. O exemplo trazido por Koch (1973), trata de um problema de proporcionalidade e regra de três, impregnado das concepções de higiene social, que justificam e familiarizam os estudantes com a prática da eutanásia: 
Uma pessoa mentalmente incapaz custa 4 Reichsmark por dia, um aleijado custa 5,5 Reichsmark por dia e um criminoso condenado, 3,5 Reichsmark. [...] dentro das fronteiras do Reich alemão 300.000 pessoas estão recebendo cuidados em instituições públicas. Quantos empréstimos matrimoniais de 1000 Reichsmark por casal poderiam ser concedidos anualmente, usando-se os fundos destinados a tais instituições? (KOCH, 1973, p. 100).

Ou ainda, o exemplo trazido por Pine (2010):

Todos os dias o estado gasta RM 6 em um aleijado; RM 4 1/4 com uma pessoa doente mental; RM $51 \frac{1}{2}$ com uma pessoa surda e muda; RM $53 / 5$ com uma pessoa de mente fraca; RM 3 1/2 com um alcoólatra; RM 4 4/5 com uma criança em um orfanato; RM 2 1/20 com uma criança em uma escola especial; RM 9/20 com uma criança em uma escola normal. Qual o custo total um aleijado e uma pessoa de mente fraca criam, se cada uma tem um tempo de vida de 40 anos? Calcule as despesas do estado para uma criança em uma escola especial e uma criança em uma escola normal, durante o período de oito anos e especifique quanto a mais uma criança em escola especial demanda (p. 49).

Os enunciados acima não só atestam o estilo pragmático militarizado do conhecimento, mas também fundamentam a naturalização dos discursos da guerra e do extermínio. O estudante fica sistematicamente exposto, em todas as disciplinas, aos mesmos temas e estilos, que constituem um discurso monológico uniformizador das formas de pensar.

Os livros didáticos contavam com exercícios que retomavam a situação histórica de crise alemã do fim da primeira guerra, para resolver cálculos de porcentagem e proporção, por exemplo:

A Alemanha teve, de acordo com o Tratado de Versalhes, que entregar todas as suas colônias. (Uma enumeração de colônias e delegações, com estimativa de população e área é dada)

A. Qual foi a perda total de população e território da Alemanha?

B. Quanto cada potência de mandato recebeu em termos de população e território?

C. Quantas vezes o território entregue é maior do que a área da Alemanha? (MANN, 1938, p. 135)

Outro exemplo de uma escolha estilística voltado para uma situação de guerra:

Quantas pessoas podem buscar proteção em um porão a prova de bombas, com comprimento de 5 metros, largura de 4 metros e altura de 2,25 metros? Cada pessoa precisa de 1 metro cúbico por hora, e eles permanecem lá por três horas. (MANN, 1938, p. 68)

Outros títulos também eram usados com o mesmo princípio estilístico de militarizar a Matemática. Dentre os citados por Mann (1938) está um dos exemplos mais contundentes do uso da matemática na doutrinação ideológica, que aparece em um enunciado de cálculo de porcentagem: 
Os judeus são alienígenas na Alemanha - Em 1933 existiam 66.060.000 habitantes no Reich Alemão, dos quais 499.682 eram judeus. Qual a porcentagem de alienígenas? (MANN, 1938, p. 68)

$\mathrm{Na}$ área da química, também referenciada como Química da Defesa, em um dos livros didáticos, o autor afirmava que os jovens deveriam ir às frentes de batalha caso um ataque acontecesse e, por isso, deveriam saber se defender de ataques com de gases. Os capítulos incluíam lições sobre diversos gases, dentre eles gases que irritavam os olhos, causavam problemas nos pulmões, na pele, etc. (MANN, 1938).

As informações trazidas até agora dizem respeito à educação masculina. O currículo feminino tinha formato diferenciado voltado, especificamente, para a formação de donas de casa, obedientes aos seus maridos e ao governo, que soubessem escolher um bom marido ariano e procriassem para a continuação de sua raça. $\mathrm{Na}$ área de física, o conteúdo era voltado para o funcionamento de equipamentos domésticos, a termodinâmica, por exemplo, era contextualizada com o funcionamento de ferros de passar, geladeiras, fogões, etc. (MANN, 1938; PINE, 2010). Com essas mudanças, o número de mulheres nas universidades caiu durante os anos em que os nazistas permaneceram no poder, voltando a subir novamente somente devido à falta de candidatos durante o período de guerra (PINE, 2010; SHIRER, 2008).

Por fim, apresentamos dois exemplos, ligados às questões raciais. $\mathrm{O}$ primeiro ligado a formação de professores, e vem do livro "A questão judaica material e seus tratamentos nas escolas" de Ernst Dobers, formador de professores da educação média, em biologia e em "Instrução Racial”" (WEGNER, 2002). Nele é apresentado um relato do exercício de reconhecimento facial, onde se identifica claramente o procedimento de discriminação racial:

Como nós queremos que nossas pessoas se pareçam? Nós colocamos dois grupos de imagens lado a lado: de um lado, corpos e faces classificados de forma nórdica, tipos esportistas, atletas Olímpicos, soldados, oficiais típicos, líderes; do outro lado, nós apresentamos um grupo de judeus, quer sejam contemporâneos ordinários ou os "grandes" de Judá, como a maioria dos líderes bolchevistas, Rosa Luxemburg, Hilferding, Eisner, Theodor Lessing, Gumbel, Stampfer, Rathenau, Theodor Wolff, Georg Bernhard, Hirschfeld, Kestenberg, ou quaisquer que sejam seus nomes. Resultará naturalmente que a criança sinta afinidade com um lado e, bastante ingenuamente, rejeição fervorosa pelo outro; essa é a questão, claro. Isso é então o objeto da palavra pedagógica falada constantemente a fortalecer e construir com conhecimento e percepção essa consciência da velha natureza da criança alemã e a completa estranheza do outro (DOBERS apud MANN, 1938, p. 79)

Outro exemplo, mostra mais claramente como a relação entre as esferas educacionais e política se manifesta em diferentes meios de comunicação. O exemplo refere-se ao texto publicado pelo jornal Der Stürmer, cujo editor Julius Streicher, também professor, produzia semanalmente editoriais antissemitas, que eram utilizadas como material instrucional nas escolas (BYTWERK, 2001). Em uma das edições do jornal foi publicado um texto enviado por uma estudante de 9 anos, que mostra como o conteúdo temático nas escolas determinava estilos na 
forma dos conteúdos específicos, nesse caso de biologia. O texto de divulgação científica e intitula-se "O cuco e o judeu":

O cuco é o judeu dentre os pássaros; pois é bem parecido com ele em aparência e também no que faz. Seu bico curvo lembra o nariz curvo do judeu. Seus pés são pequenos e fracos, motivo pelo qual não pode andar facilmente no chão. O mesmo é verdade para os judeus, que também não têm uma bela forma de caminhar. Quando esse pássaro chama "Cuco! Cuco!" faz o mesmo gesto que um comerciante judeu tentando mostrar suas boas maneiras para que o alemão compre dele. Ambos esses judeus, tanto os pássaros quanto os humanos, são parasitas, isso é, eles desejam se tornar ricos e gordos as custas dos outros [...] Mas nós, seres humanos não somos tão estúpidos quanto os pássaros. Nós não vamos defender isso e estamos expulsando o cuco impertinente do nosso país. Nós, crianças de Roth, ajudamos o máximo que conseguimos para alcançar esse objetivo. Um grupo da nossa classe fica sempre em frente ao armazém Baer; então quando os compradores querem entrar, as crianças gritam: "Você não tem vergonha de comprar de um judeu? Sim!" e então a mulher fica vermelha no rosto e vai embora. Heil Hitler. (MANN, 1938, p. 84)

Ao final da carta, a estudante ainda agradece a sua professora, a quem dá todos os méritos por aprender essa forma de ver o mundo.

Essa cultura discriminatória e antissemita se estendia para vários campos do saber, inclusive no campo da arte (BARRON; GUENTHER, 1991; PETROPOULOS, 2014). A "Sociedade Nacional Socialista da Cultura Alemã", formada em 1930 e, posteriormente, chamada de "Defesa da Cultura Alemã", tinha como objetivo "higienizar" a arte moderna com suas figuras "degeneradas" que mostravam a "doença mental dos seus criadores", normalmente associados à judeus (BARRON; GUENTHER, 1991, 11). O arquiteto nazista Paul SchultzeNaumburg realizava palestras pela Alemanha, no início dos anos 1930, mostrando a arte moderna "degenerada" por meio de comparações com "fotografias de pessoas com deformações corporais. Ligava a degeneração humana à perversão da arte moderna" (BARRON; GUENTHER, 1991, 12).

\section{CONCLUSÃO}

Neste trabalho, apresentamos o estudo de um caso extremo de controle social por meio da escola, exercido pela Educação Nazista, no período anterior à segunda guerra mundial. A escola, neste caso, assim como em outros, deixa de ser apenas um centro de formação para o mercado de trabalho e passa a ser, mais explicitamente, um local para determinar modos de comportamento e valores ligados a uma estrutura socioeconômica que recebeu e posteriormente deu suporte a doutrina nazista - uma escola nazista. Essa transformação se fez por meio de políticas que modificaram aspectos da escola à época, as quais vão desde as formas de acesso até a diferenciação do currículo por gênero.

Sendo a escola o local de formação de novos intelectuais e de elaboração da vida cultural, qualquer alteração em sua estrutura física e curricular indicam uma tentativa de mudança na cultura e na sociedade. As mudanças que aconteceram no 
sistema educacional alemão entre 1933 e 1939 demonstram uma clara tentativa de conquistar a juventude e transformar a cultura do país com base nos ideais nazistas propostos por Hitler em seu livro Minha Luta.

A escola teve o papel fundamental de correia de transmissão para ensinar os ideais nazistas aos jovens. Ao dividir o currículo entre masculino e feminino, definiu-se papéis sociais delimitados que cada um dos gêneros deveria cumprir na nova sociedade. Não mais o currículo de ciências tinha o objetivo de atrair crianças para os estudos científicos ou contribuir para o crescimento tecnológico do país. Para os jovens rapazes, foi utilizado como uma das ferramentas de incentivo aos estudos da ciência da guerra, que se concretizavam na física, por meio dos enunciados em estudos sobre lançamento de bombas e, na química, pelo estudo da composição e dos efeitos fisiológicos de gases tóxicos. A matemática estabelecia um ensino contextualizado em problemas sociais e econômicos do Estado alemão. Esta temática se revela na composição e no estilo dos exercícios introduzidos pelos livros didáticos, cujo exemplo, talvez o mais chocante, apresentado neste texto, compara os gastos governamentais com minorias ou populações, tais como doentes, deficientes ou judeus, que produziriam despesas excessivas para estado, dando a entender, que a solução para a redistribuição desta renda, entre o povo ariano, era a da eliminação dessas populações.

O uso da física para os objetivos militares revela que a formação de soldados não era desenvolvida exclusivamente por meio do intenso treinamento físico, mas também por meio do ensino de uma ciência tematizada na guerra. Afinal, era necessária a formação de engenheiros e guerrilheiros capazes de dominar o conhecimento da física para produzir armamentos, veículos e outros equipamentos que suprissem as necessidades de guerra. Para tanto, seja para a formação de soldados ou engenheiros, não somente a física, mas as outras disciplinas escolares, também foram modificadas para estabelecer uma mudança cultural cujo objetivo, em um futuro próximo, era a formação de adultos preparados para entrar em batalha por seu país, pela pureza de sua raça e pela dominação ou extermínio dos povos considerados inferiores ou que pretendessem impedir os objetivos de nazista.

O ensino às jovens, por sua vez, não se voltava diretamente para a tecnologia das armas de guerra; nesse caso, o interesse era o de educar as mulheres para dar continuidade ao crescimento da nova geração de jovens que serviria aos mesmos propósitos dos pais, serem soldados, engenheiros ou futuras mães e donas de casa.

Os professores tinham um papel central na formação das crianças e na disseminação da ideologia do partido. Assim, eram praticamente obrigados a participar da Liga dos Professores e apropriarem-se dos preceitos necessários para uma educação nazista de modo que pudessem ensiná-los aos seus alunos. Obrigatoriamente, deviam fazer parte de um grupo comandado por agentes do governo, caso contrário eram expulsos da escola ou não eram contratados. Fora da escola, os jovens eram obrigados a participar de atividades que faziam os ideais nazistas parecerem os únicos existentes. Como não tinham acesso a outras formas de pensar, a forma apresentada acabava por ser naturalizada, de modo que passavam a acreditar que era a única forma de se viver.

Alguns passos na imposição de uma nova ideologia podem ser percebidos mais claramente no caso estudado e podem servir como parâmetros para análises 
críticas das condições atuais. O principal deles advém do entendimento da análise de discurso bakthiniana de que os seres humanos falam em gêneros que dependem de seu contexto sócio-cultural-histórico e que estão intimamente ligadas à visão de mundo. Ao imergir uma nova geração em um gênero de discurso particular, o Partido Nazista pretendia restringir as possibilidades de pensamento livre, onde os jovens não mais poderiam pensar por si mesmos, mas seriam restringidos a um pensamento embebido de uma única ideologia, de uma única visão de mundo, a partir da qual outras visões estariam equivocadas e deveriam ser eliminadas.

Fica claro, a partir da perspectiva gramscianas e foucaultianas de que a escola serve como uma correia de transmissão do estado. Daí a necessidade de atentarmos para as ideias, hoje correntes, que pretendem restringir os discursos ensinados em sala de aula, uma vez que somente a pluralidade de ideias pode dar uma visão de mundo abrangente e tolerante (FAIRCLOUGH, 2001). A materialização dessas restrições pode se dar em materiais didáticos e nas próprias condições de trabalho dos professores (CASSAB, 2003; FERREIRA-COSTA; PEDRO-SILVA, 2019). Como vimos, os livros utilizados em sala reforçavam o discurso nazista, antissemita e pretendiam desenvolver, nos estudantes, a vontade de usar armas de fogo para defender seu país. Assim, é fundamental que se estabeleçam análises críticas tanto de materiais didáticos promovidos por governos autoritários, como das condições de trabalho dos professores (e.g. condições salariais, materiais, de saúde e liberdade de cátedra), principalmente porque são base para a formação dos novos intelectuais críticos.

O momento político em que vivemos requer reflexões contínuas, intensivas e críticas, sobre o que é ciência e como ela vem sendo utilizada dentro e fora das salas de aula. Nos livros didáticos e avaliações massivas atuais, é possível identificar exercícios e problemas que, em um primeiro momento, parecem tradicionais e inofensivos como, por exemplo, aqueles relacionados ao estudo de lançamentos oblíquos no estudo de projéteis, que expressam uma antiga tradição do uso da física como instrumento de guerra. Um exemplo de descontextualização da atividade social, da descaracterização da violência e da condição política em exercícios de física é o do problema apresentado a seguir, cuja resolução se reduz a um problema de cinemática, atribuindo uma neutralidade à física que fica reduzida apenas à resolução matemática. A contextualização dessa questão de vestibular, que aparece largamente nos materiais utilizados em escolas, deveria ser problematizada, explicitada, apresentada criticamente e mediada nas atividades didáticas a que se destina, pelos profissionais da educação. 
Questão 17: A figura a seguir mostra uma das cenas vistas durante a Copa das Confederações no Brasil. Os policiais responderam às ações dos manifestantes com bombas de gás lacrimogêneo e balas de borracha em uma região totalmente plana onde era possivel avistar a todos. Suponha que o projétil disparado pela arma do PM tenha uma velocidade inicial de 200,00 m/s

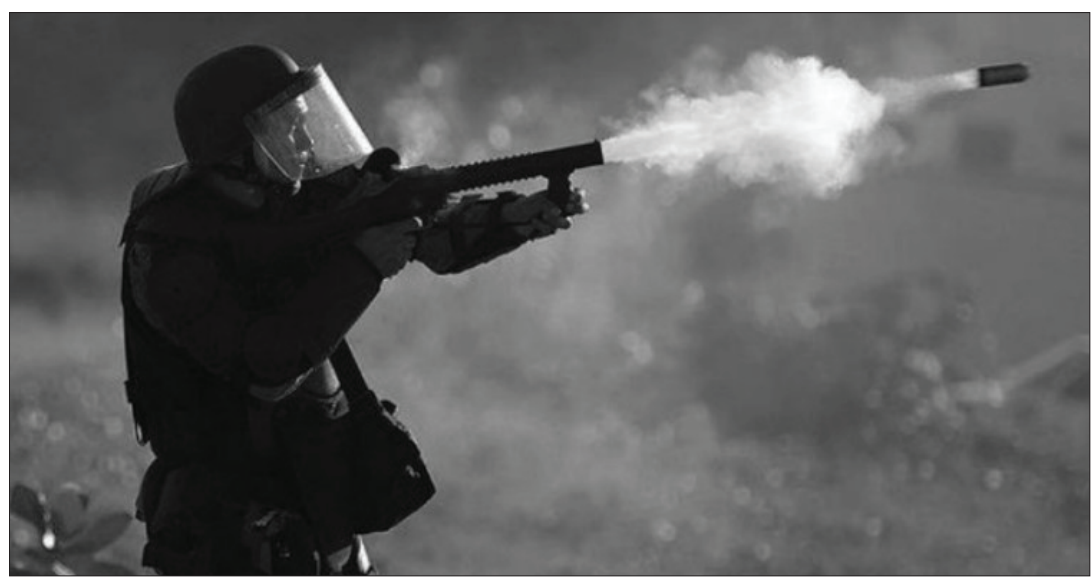

(Fonte: http://noticias.uol.com.br/ultimasnoticias/efe/2013/09/07/protestos-em-saopaulo-terminam-com-violencia-e-confrontos.htm).

Suponha que o projétil disparado pela arma do PM tenha uma velocidade inicial de 200,00 m/s ao sair da arma e sob um ângulo de 30,00 com a horizontal. Calcule a altura máxima do projétil em relação ao solo, sabendo-se que ao deixar o cano da arma o projétil estava a 1,70 $\mathrm{m}$ do solo. Despreze as forças dissipativas e adote $\mathrm{g}=10,00 \mathrm{~m} / \mathrm{s}^{2}$. (UNIFOR, 2014, 10)

Todas as ciências, assim como toda a produção do conhecimento humano, emergem e se desenvolvem embebidas em ideologias, as quais, intencionalmente ou não, raramente são explicitadas para os estudantes que, por sua vez, passam a naturalizar certos modos de pensar o papel da ciência no mundo. Assim, nesse estudo, nossa intenção é a de apresentar a História da Ciência e da Educação como instrumento especular sobre as formas com que estamos produzindo o presente e o futuro. Esperamos que a história nos forneça parâmetros para estabelecer relações críticas entre a ação de um estado autoritário, muitas vezes ilegítimo, sobre os processos educacionais populares e as possíveis formas de emancipação de um povo.

\section{AGRADECIMENTOS}

Cristiano Mattos agradece ao CNPq pelo apoio financeiro (processo 302100/2019-9) e ao Dr. Frank Kohl pelo apoio, em território alemão, na obtenção do livro de Günther (1936). 


\section{REFERÊNCIAS}

ANDRADE, R. Resistência à ciência. Rev Pesq FAPESP. v. 20. n. 284. p 16-21. 2019.

BADIA, G.; PORTELA, P. Introducción a la ideología nacional-socialista. Madrid: Ed. Ayuso, 1971.

BAKHTIN, M.M. Estética da criação verbal. São Paulo, SP: Martins Fontes, 2003.

BALL, P. Serving the Reich: the struggle for the soul of physics under Hitler. Chicago: The University of Chicago Press, 2014.

BARRON, S; GUENTHER, P. The fate of the avant garde in Nazi Germany. Los Angeles: County Museum of Art \& Art Institute of Chicago, 1991.

BEYERCHEN, A.D. Scientists under Hitler: politics and the physics community in the Third Reich. New Haven: Yale University Press, 1977.

BOURDIEU, P. The Logic of Practice. Stanford: Stanford University Press, 1990.

BYTWERK, R.L. Julius Streicher: Nazi editor of the notorious anti-Semitic newspaper Der Stürmer. 1st Cooper Square Press ed. NY: Cooper Square Press, 2001.

CAMILLO, J.; MATTOOS, C.R. Ensaio sobre as relações entre Educação, Ciência e Sociedade a partir da perspectiva do desenvolvimento humano. Linhas Críticas, v.25. 2019.

CARR, E.H. Que é história. Rio de Janeiro, RJ: Paz e Terra., 1992.

CARR, E.H. Vinte anos de crise (1919-1939). Brasília: UnB Editora, 2001.

CASSAB, M. Significando o livro didático: com a palavra, os professores de ciências. 2003. Dissertação (Mestrado). Núcleo de Tecnologia Educacional para a Saúde. Rio de Janeiro: UFRJ.

COHEN, P. Arquitetura da Destruição. Sandrew, 1991.

EPSTEIN, C. Nazi Germany: confronting the myths. Chichester, West Sussex, UK; Malden, MA, USA: WILEY Blackwell, 2015.

EUA. Nazi Conspiracy and Aggression. Washington: U.S. Gov. Print. Office, 1946.

EVANS, R. A Chegada do Terceiro Reich. $3^{a}$ ed. São Paulo: Planeta, 2016.

FAIRCLOUGH, N. Discurso e mudança social. Brasília: Editora da UnB, 2001

FERNANDES, L. Ciência, Tecnologia e Inovação: a 'operação desmonte' e seus resistentes. Disponível em: https://www.nexojornal.com.br/ensaio/2020/Ciência-Tecnologia-e-Inovação-a'operação-desmonte'-e-seus-resistentes. Acesso em: 17 jan. 2020.

FERREIRA-COSTA, R.Q.; PEDRO-SILVA, N. Níveis de ansiedade e depressão entre professores do Ensino Infantil e Fundamental. Pro-Posições, Campinas, v.30, e20160143, 2019. https://doi. org/10.1590/1980-6248-2016-0143.

FOLHA. Corte orçamentário de $42 \%$ em ciência e tecnologia preocupa entidades. Disponível em: <https://www1.folha.uol.com.br/ciencia/2019/04/corte-orcamentario-de-42-em-ciencia-etecnologia-preocupa-entidades.shtml>. Acesso em: 17 jan. 2020. 
FOUCAULT, M. A arqueologia do saber. RJ: Forense Universitária, 2008.

FOUCAULT, M. Microfísica do Poder. 13ª ed. RJ: Graal, 1998.

FOUCAULT, M. Vigiar e punir: nascimento da prisão. Petrópolis: Vozes, 1987.

GOODSON, I. F. O currículo em mudança estudos na construção social do currículo. Tradução: Jorge Ávila De Lima. Porto: Porto Editora, 2001.

GRAMSCI, A. Cadernos do cárcere. $11^{a}$ ed., v. 1. Tradução: Carlos Nelson Coutinho. Rio de Janeiro: Civilização Brasileira, 2019.

GRAMSCI, A. Cadernos do cárcere. $2^{\mathrm{a}}$ ed., v. 2. Tradução: Carlos Nelson Coutinho. Rio de Janeiro: Civilização Brasileira, 2001.

GUILHERME, A.A.; PICOLI, B.A. Escola sem Partido. Rev. Bras. Educ. v. 23. 2018.

GÜNTHER, E. (ed.). Wehrphysik: Ein Handbuch für Lehrer. Frankfurt: Moritz Diesterweg, 1936.

HEATER, D.B. Citizenship: The Civic Ideal in World History, Politics and Education. 3. ed. Manchester: Manchester Univ. Press, 2004.

HEISENBERG, W. A parte e o todo: encontros e conversas sobre física, filosofia, religião e política. Tradução: Vera Ribeiro. Rio de Janeiro: Contraponto, 1996.

HENTSCHEL, K. Physics and National Socialism: An Anthology of Primary Sources. Tradução: Ann Hentschel. Basel; Boston: Birkhäuser Verlag, 1996.

HITLER, A. Mein Kampf. New York: Reynal \& Hitchcock, 1941.

HOBSBAWM, E.J. Era dos extremos: o breve século XX; 1914 - 1991. 2ª ed. Tradução: Marcos Santarrita. São Paulo: Companhia das Letras, 2005.

HOLLAND, A. Europa Europa ou Hitlerjunge Salomon. CCC Film, 1990. Disponível em: http://y2u.be/wwRpyZuJJzQ. Acesso em: 01 abr. 2017.

KOCH, H.W. A juventude hitlerista: Mocidade traída. Tradução: Edmond Jorge. Rio de Janeiro: Ed. Renes, 1973.

LENARD, P. Deutsche Physik in vier bänden. Munique: J.F. Lehmann, 1936.

LÉVI-STRAUSS, C. Antropologia estrutural. RJ: Tempo Brasileiro, 1989.

LEWY, G. Harmful and undesirable: book censorship in Nazi Germany. New York, NY: Oxford University Press, 2016.

LUTZ, R. H. The German Revolution: 1918-1919. CA: Stanford Uni Press, 1922.

MANN, E. School for Barbarians. New York: Dover Publication, 1938.

MARROU, H.I. A History of Education in Antiquity. Tradução: G Lamb. Madison, Wis: University of Wisconsin Press, 1982.

MCNAMARA HORVAT, E.; LISING ANTONIO, A. Hey, those shoes are out of uniform: African American girls in an elite school and the importance of habitus, Anthropology and Education Quarterly v.30, n.3, p. 319-341, 1991. 
MEDVIÉDEV, P.N. O método formal nos estudos literários: Introdução a uma poética sociológica. SP: Contexto, 2010.

MESZAROS, I. A educação para além do capital. São Paulo: Boitempo, 2008

MUSGROVE, F. The Contribution of Sociology to the Study of the Curriculum. In: J. Kerr (Ed.). Changing the Curriculum. London: Hazell Watson \& Viney, 1968.

ORTEGA, J.; RODRIGUES, A.M.; MATTOS, C.R. Revisitando Projetos de Ensino de Física numa Perspectiva bakhtiniana. Inves. Ensino de Ciências. v. 22. n. 3. p 16. 2017.

PETROPOULOS, J. Artists Under Hitler: Collaboration and Survival in Nazi Germany. Yale: Yale University Press, 2014.

PINE, L. Education in Nazi Germany. Oxford: Berg, 2010.

PINE, L. Hitler's 'National Community': Society and Culture in Nazi Germany. London: Bloomsburry Academic, 2017.

SACRISTÁN, J. G. O que significa o currículo? In: SACRISTÁN, J. G. Saberes e Incertezas sobre o Currículo. SP: Penso, 2013.

SEGAL, S.L. Mathematicians under the Nazis. Princeton: Princeton Unviversity Press, 2014.

SHIRER, W. L. Triunfo e consolidação. v.1. Trad: Pedro Pomar. RJ: Agir, 2008

SPINELLI, M. O ciclo de estudos básicos da escolaridade Grega. Educação e Filosofia. v.27. n. 54. p. 603-646. 2016.

STERN, F.R. El mundo alemán de Einstein: la promesa de una cultura. Barcelona: Paidós Ibérica, 2003.

UNIFOR. Processo Seletivo 2014: $1^{\text {a }}$ Fase: MEDICINA. Disponível em https://vestibular. brasilescola.uol.com.br/downloads/universidade-fortaleza.htm. Acesso em 01 abr. 2020.

VOLÓCHINOV, V. Marxismo e filosofia de linguagem. SP: Ed. 34, 2017.

WEGNER, G.P. Anti-semitism and Schooling Under the Third Reich. NY: Abingdon, 2002.

\section{NOTAS}

1 Dentre as funções apresentadas pela a escola ao longo do tempo estão: as comunidades tidas como primitivas não possuíam uma instituição escolar, embora prezassem pela aprendizagem de atividades necessárias para a vida coletiva (como caçar, colher, cantar, ritualizar); enquanto na Grécia antiga seu papel era formar os dirigentes da sociedade; na Idade Média a escola estava circunscrita aos espaços religiosos etc. (HEATER, 2004; LÉVI-STRAUSS, 1989; MARROU, 1982; SPINELLI, 2016).

2 O ex-Ministro da Educação do Brasil, Abrahan Weintraub, em relação ao Programa Nacional do Livro Didático, que investe anualmente aproximadamente $\mathrm{R} \$ 2$ bilhões anuais para comprar e distribuir 165 milhões de livros didáticos aos estudantes da escola pública, reteewton o Presidente Jair Bolsonaro: "livro didático no governo Jair Bolsonaro: mais barato e sem ideologia política ou de gênero", postando na mesma publicação um vídeo afirmando que o livro "não vai ter ideologia, ponto" (https://twitter.com/AbrahamWeint - 12 jan 2020). 
3 Apesar de ser um livro escrito no período, as informações que utilizamos de Mann são sobre livros didáticos.

4 Os documentos foram digitalizados e estão disponíveis na Biblioteca do Congresso dos EUA, link na referência.

5 A perspectiva bakthiniana diz respeito aos trabalhos desenvolvidos pelo círculo de Bakhtin, ou seja, além das obras escritas por Bakhtin, utilizamos também as elaboradas por Volóchinov. Essa metodologia, preconiza a análise das formas enunciativas em ligação com as relações concretas em que se realiza (VOLÓCHINOV, 2017).

6 Algumas obras são bons exemplos de estilos do período, como Holland (1990) e Cohen (1991).

7 Hitlerjugend.

8 Bund Deutscher Mädel.

9 A proporção de mulheres nas universidades diminuiu até o início da Guerra, em setembro de 1939 , para $20 \%$ da população universitária total, porém, devido ao aumento dos alistamentos dos homens, essa proporção cresceu $30 \%$ em um ano, chegando a quase $50 \%$ no biênio de 1943 1944 (PINE, 2017). Em números absolutos, a quantidade de mulheres nas universidades que havia chegado a 6.342 no início da Guerra em 1939, passou para 42.210 em 1944 (HENTSCHEL, 1996).

10 Tendências hereditárias se referem ao ensino de biologia, que foi priorizado no período e versava, principalmente, sobre as diferenças raciais entre judeus e arianos; o caráter foi um tema amplamente tratado no livro de Hitler (1941), onde acreditava-se que os jovens deveriam aprender sobre como tomar decisões e ter apreço pelas responsabilidades; por fim, a constituição física tomou grande parte do currículo, trataremos do assunto adiante.

11 National-Sozialistischer Lehrerbundes.

12 Wehrphysik: Ein Handbuch für Lehrer.

13 Deutsche Physik in vier bänden.

14 Massa e alça de mira são partes da arma utilizada para garantir maior precisão para acertar o alvo.

15 Figura 2 neste trabalho.

\section{Submetido em 16/03/2020}

Aprovado em 25/06/2020

\section{Contato:}

Instituto de Física

Universidade de São Paulo

R. do Matão, n. 1371 - Butantã

CEP 05.508-090 - São Paulo, SP - Brasil 